\title{
Ontogeny of $\beta$-Adrenergic Regulation of Adenylate Cyclase in Intrapulmonary Arteries from Fetal and Postnatal Lambs
}

\author{
PHILIP W. SHAUL, MELODY A. FARRAR, AND L. MAXIMILIAN BUJA \\ Departments of Pediatrics and Pathology, University of Texas Southwestern Medical Center at Dallas, \\ Dallas, Texas 75235
}

\begin{abstract}
The enzyme adenylate cyclase is critically involved in the regulation of vasodilatation in the developing pulmonary circulation in that it mediates the vascular smooth muscle effects of $\beta$-adrenergic agonists and vasodilatory prostaglandins. These agonists activate receptors coupled to the catalytic subunit of the enzyme by stimulatory guanine nucleotide-dependent regulatory proteins. We examined the ontogeny of the function of the adenylate cyclase system in intrapulmonary arterial segments from fetal lambs at 110-115 (F1) and 125-135 d gestation (F2) and from postnatal lambs at 7-14 (P1) and 35-56 d of age (P2). The function of the intact enzyme system and its components was assessed in incubations measuring cAMP accumulation during phosphodiesterase inhibition. $\beta$-Adrenergic mediation of adenylate cyclase was examined because the binding characteristics of the smooth muscle receptors can be readily quantified. Nonstimulated (basal) cAMP accumulation was similar in $F 1$ and $F 2$, it increased 8 -fold from $F 2$ to P1, and it was equivalent in P1 and P2. cAMP accumulation with isoproterenol increased 5.9-fold from F1 to F2 and was similar in F2, P1, and P2. Radioligand binding studies revealed that the greater response to isoproterenol in $F 2$ versus $F 1$ is not related to an increase in $\beta$-adrenergic receptor density or affinity. cAMP accumulation with forskolin, which activates adenylate cyclase by actions that involve both the stimulatory guanine nucleotide-dependent regulatory protein and the catalytic subunit, was similar in the four age groups, indicating that there are no maturational changes in the function of these enzyme system components. As such, the enhancement in $\beta$-adrenergic mediation of the enzyme during the 3rd trimester may be related to changes in receptor-guaninne nucleotide-dependent regulatory protein coupling. It is concluded that there are marked developmental alterations in the function of the adenylate cyclase system in the intrapulmonary arteries during late gestation that may serve to optimize the capacity of this mediator of pulmonary vasodilatation in the perinatal period. (Pediatr Res 30: 610$615,1991)$
\end{abstract}

\section{Abbreviations}

$G$ protein, guanine nucleotide-dependent regulatory protein $G_{s}$, stimulatory $G$ protein

VSM, vascular smooth muscle

F1, fetal lambs 110-115 d gestation

F2, fetal lambs 125-135 d gestation

Received October 15, 1990; accepted July 16, 1991

Correspondences and reprint requests: Dr. Philip W. Shaul, Department of Pediatrics, University of Texas Southwestern Medical Center at Dallas, 5323 Harry Hines Blvd., Dallas, Tx 75235 .

Supported by the American Heart Association, Texas Affiliate (no. 88G-113) and by National Institutes of Health Grants HD-08783 and HL-34150.
P1, postnatal lambs 7-14 d of age

$P 2$, postnatal lambs 35-56 d of age

IBMX, isobutylmethylxanthine

$\left[{ }^{125} \mathrm{I}\right] \mathrm{ICYP},\left[{ }^{125} \mathrm{I}\right]$ iodocyanopindolol

$B_{\text {max }}$, receptor density

cGMP, cyclic GMP

The plasma membrane-bound enzyme adenylate cyclase is critically involved in the regulation of vasodilatation in the developing pulmonary circulation. Stimulators of adenylate cyclase activity in VSM such as $\beta$-adrenergic agonists and vasodilatory prostaglandins, including prostacyclin, prostaglandin $E_{2}$, and prostaglandin $E_{1}$, elicit pulmonary vasodilatation in the late fetal and newborn lamb (1-4). In addition, vasoconstriction occurs with inhibition of the synthesis of endogenous agonists for adenylate cyclase (i.e. vasodilatory prostaglandins) (5). This enzyme may also be important in the attenuation of acute hypoxic pulmonary vasoconstriction in the perinatal period because acute hypoxia stimulates pulmonary prostacyclin synthesis (6) and the inhibition of prostaglandin production augments the vasoconstrictor response (7). Furthermore, because the inhibition of prostaglandin synthesis also attenuates the normal decline in pulmonary vascular resistance at the time of birth $(8,9)$, endogenous agonists of adenylate cyclase may contribute to the successful transition of the pulmonary circulation from that of the fetus to that of the newborn.

The adenylate cyclase system is composed of stimulatory and inhibitory receptors that are coupled to stimulatory and inhibitory $\mathrm{G}$ proteins. The $\mathrm{G}$ proteins are coupled to the catalytic subunit of the enzyme, which converts ATP to cAMP when activated (10). $\beta$-Adrenergic agonists and vasodilatory prostaglandins enhance arterial adenylate cyclase activity by activating their respective stimulatory receptors $(10-12)$.

The purpose of the present investigation was to examine the ontogeny of the function of the adenylate cyclase system in intrapulmonary arteries during the late fetal and early postnatal period in the lamb, a time in development during which there is a dramatic increase in the capacity for pulmonary vasodilatation in response to a variety of stimuli such as oxygen $(13,14)$. The function of the enzyme system was assessed in intact arterial segments by determining cAMP accumulation during inhibition of cyclic nucleotide breakdown by phosphodiesterases (15-20). Developmental changes in basal (nonstimulated) cAMP accumulation were examined, as were changes in $\beta$-adrenergic receptor-mediated and postreceptor-stimulated cAMP accumulation to discern the ontogeny of the function of the components of the adenylate cyclase system. $\beta$-Adrenergic stimulation was studied because the binding characteristics of the $\beta$-adrenergic VSM receptor can be readily determined, whereas the quantification 
of VSM prostaglandin receptors is not well established (21). We tested the hypothesis that the function of the adenylate cyclase system in the intrapulmonary arteries increases during the late fetal and early postnatal period.

\section{MATERIALS AND METHODS}

Animal model. The fetal and newborn lamb has been used extensively by several groups of investigators in studies examining physiologic parameters to assess the ontogeny of the regulation of pulmonary vasomotor tone $(13,14,22)$. As such, it is an appropriate animal model for the study of the ontogeny of the biochemical mechanisms mediating pulmonary vasodilatation. cAMP accumulation was studied in intrapulmonary arterial segments from four different groups of fetal and postnatal lambs. They were fetal lambs at $110-115 \mathrm{~d}$ gestation (F1, $n=6)$, fetal lambs at $125-135 \mathrm{~d}$ gestation (F2, $n=6$ ) (with term being 144 $\pm 3 \mathrm{~d}$ ), postnatal lambs at $7-14 \mathrm{~d}$ of age (P1, $n=3)$, and postnatal lambs at $35-56 \mathrm{~d}$ of age $(\mathrm{P} 2, n=4)$. $\beta$-Adrenergic receptor binding characteristics were quantified in intrapulmonary arteries from an additional three sets of $F 1$ fetuses (tissues were pooled from twins or triplets) and from three F2 fetuses. Before they were killed the pregnant ewes were housed in the Animal Resources Center of the University of Texas Southwestern Medical Center and were given standard animal food and water ad libitum. The newborn sheep that were housed with the ewes began feeding on solid food at 2 to $3 \mathrm{wk}$ of age. The procedures followed in the care and euthanasia of the study animals were approved by the Institutional Review Board for Animal Research.

Arterial segment preparation. The ewe and fetus(es) were euthanized with sodium pentobarbital $(50 \mathrm{mg} / \mathrm{kg})$ given i.v. to the ewe, and the fetuses were delivered by cesarean section. The newborn sheep were euthanized in a similar manner. The thoracic contents were immediately removed en bloc and were placed in ice-cold PBS (0.01 $\mathrm{M} \mathrm{PO}_{4}, 0.15 \mathrm{M} \mathrm{NaCl}$, at pH 7.4). Further tissue preparation was performed in a cold room at $4^{\circ} \mathrm{C}$. The pulmonary arterial tree was rapidly dissected from the lung parenchyma and was placed in fresh ice-cold PBS. Fatty and connective tissue was gently removed and the adventitia was grossly dissected from the arteries, with care taken not to disrupt the endothelium.

Arterial segments weighing 5 to $10 \mathrm{mg}$ were cut from the 4 thgeneration intrapulmonary arteries for use in the incubations for cAMP accumulation (23). cAMP accumulation was studied in intact segments in lieu of examining adenylate cyclase enzyme activity directly in microsomal preparations because receptor uncoupling can occur during the preparation of membranes from smooth muscle (24). The VSM for the determinations of $\beta$ adrenergic receptor binding characteristics was obtained from 4th- through 6th-generation intrapulmonary arteries after the removal of the endothelium with a cotton-tipped applicator (23). The generations of arteries studied were selected in an effort to examine these parameters close to the level of the resistance vessels (23). The presence or absence of intact endothelium was confirmed by light microscopy of $5-\mu \mathrm{M}$ sections of randomly chosen segments and studies of endothelium-dependent acetylcholine stimulation of VSM cGMP production $(25,26)$. Before endothelium removal, 1-min incubations of segments from F2 fetal lambs in the presence of $10 \mu \mathrm{M}$ acetylcholine resulted in a 4- to 5-fold increase in arterial segment cGMP content. In contrast, acetylcholine had no effect on cGMP content in segments incubated after endothelium removal.

Incubations for CAMP accumulation. The cAMP content of untreated intrapulmonary arterial segments was determined after equilibration of the segments in $1.0 \mathrm{~mL}$ of freshly prepared Krebs-Henseleit buffer gassed with $95 \% \mathrm{O}_{2} / 5 \% \mathrm{CO}_{2}$ in polypropylene tubes at $37^{\circ} \mathrm{C}$. The buffer contained $4.8 \mathrm{mM} \mathrm{KCl}, 2.0$ $\mathrm{mM} \mathrm{CaCl}_{2}, 1.2 \mathrm{mM} \mathrm{KH}_{2} \mathrm{PO}_{4}, 1.2 \mathrm{mM} \mathrm{MgSO}, 11.0 \mathrm{mM}$ dextrose, $118 \mathrm{mM} \mathrm{NaCl}, 25 \mathrm{mM} \mathrm{NaHCO}$, and $0.5 \mathrm{mM}$ ascorbic acid at a $\mathrm{pH}$ of 7.4 , and the resulting $\mathrm{PO}_{2}$ with gassing was 90.4 $90.6 \mathrm{kPa}(678-680 \mathrm{~mm} \mathrm{Hg})$. The $\mathrm{PO}_{2}$ did not fall significantly for at least $20 \mathrm{~min}$ after gassing, which was the maximum duration of equilibration or incubation. The segments were equilibrated and studied at a $\mathrm{PO}_{2}$ of $90.6 \mathrm{kPa}(680 \mathrm{~mm} \mathrm{Hg})$ in an effort to have equivalent in vitro conditions for all four groups, excluding the in vivo oxygenation status of the fetal or newborn lamb as a variable. The cAMP content of untreated segments was stable after $10 \mathrm{~min}$ of equilibration, and the values reported are after $20 \mathrm{~min}$ of equilibration. At the end of the 20 -min period, the equilibration media was aspirated from the tube, 1.0 $\mathrm{mL}$ of ice-cold $7 \%$ trichloroacetic acid was added to the tube containing the arterial segment, and it was placed on ice. The segment was frozen in trichloroacetic acid until homogenization and the determination of cAMP content were performed.

Basal (nonstimulated) cAMP accumulation was determined during the incubation of arterial segments in fresh oxygenated Krebs-Henseleit buffer in the presence of $100 \mu \mathrm{M}$ IBMX to inhibit the metabolism of cAMP by phosphodiesterases. The methods used were modified from those previously used in studies of tracheal smooth muscle, coronary artery, and aorta $(15-20)$. The concentration of IBMX used inhibits arterial phosphodiesterase activity by at least $80-90 \%$, and the effect is constant for up to $30 \mathrm{~min}(16-18)$. At the end of the incubation period, the media was removed and the segments were treated and stored as described above. The amount of cAMP accumulated in the arterial segments during incubation in the presence of IBMX was determined by subtracting the cAMP content of equilibrated, untreated segments.

cAMP accumulation with exogenous stimulation of the adenylase cyclase system was also examined during incubations of the arterial segments in the presence of IBMX. $\beta$-Adrenergic receptor-mediated cAMP accumulation was determined in incubations with $10 \mu \mathrm{M}$ isoproterenol (18). This concentration yielded maximal cAMP accumulation in preliminary experiments. Postreceptor-stimulated cAMP accumulation was determined in incubations in the presence of $100 \mu \mathrm{M}$ forskolin (27), which activates the adenylate cyclase system by actions that involve both $\mathrm{G}_{\mathrm{S}}$ and the catalytic subunit $(28,29)$. Preliminary experiments were performed that established that the maximal effect of forskolin was obtained at this concentration. The termination of these incubations and the calculations of the amount of CAMP accumulated followed the procedures outlined above.

$C A M P$ assay. The frozen arterial segments were thawed on ice and were homogenized in ground glass using a motorized pestle. Duplicate aliquots of homogenate were set aside for protein determination by the Lowry method using BSA as the standard (30). The remainder of the homogenate was centrifuged at $4^{\circ} \mathrm{C}$ at $1300 \times g$ for $15 \mathrm{~min}$ and an ether extraction was performed on $50 \mu \mathrm{L}$ of the supernatant $(10 \times$ volume, three times). The ether-extracted supernatant was dried at $40^{\circ} \mathrm{C}$ for 12 to $16 \mathrm{~h}$, and cAMP content was determined by RIA after acetylation $(31,32)$. The intraassay and interassay coefficients of variation for the cAMP RIA were 3.6 and $7.8 \%$, respectively.

$\beta$-adrenergic receptor radioligand binding studies. The methods used generally follow those previously described in detail for the study of $\beta$-adrenergic receptors in rat VSM (32). The intrapulmonary VSM was transferred into ice-cold $0.25 \mathrm{M}$ sucrose buffer, $\mathrm{pH} 7.4$, with $10 \mathrm{mM}$ Tris $(3 \times$ volume $)$. The tissue was washed in the sucrose buffer twice, and the plasma membranes were prepared at $4^{\circ} \mathrm{C}$ by methods modified from those of Wei et al. (33). The tissue was minced with scissors and was homogenized twice with a Polytron at setting no. 8 for $10 \mathrm{~s}$. The homogenate was centrifuged at $4^{\circ} \mathrm{C}$ at $1500 \times g$ for $10 \mathrm{~min}$, and the resulting supernatant was filtered through two layers of gauze and centrifuged at $4^{\circ} \mathrm{C}$ at $100000 \times g$ for $30 \mathrm{~min}$. The pellet formed was resuspended in $5.0 \mathrm{mM} \mathrm{N}$-2-hydroxyethylpiperazine$N^{\prime}$-2-ethanesulfonic acid buffer, $\mathrm{pH} 7.4$, with $1.0 \mathrm{mM} \mathrm{MgSO}_{4}$, yielding a protein concentration of 50 to $100 \mu \mathrm{g} / \mathrm{mL}$ as determined by the Lowry method (30). 
$\beta$-Adrenergic receptor binding assays were performed with 100 $\mu \mathrm{L}$ of membrane preparation in a total volume of $500 \mu \mathrm{L}$ of the $5.0 \mathrm{mM} N$-2-hydroxyethylpiperazine- $N^{\prime}$-2-ethanesulfonic acid buffer. The $\beta$-adrenergic receptor-specific radiolabeled antagonist $\left[{ }^{125} \mathrm{I}\right] \mathrm{ICYP}$ was used. The purity of each $\left[{ }^{125} \mathrm{I}\right] \mathrm{ICYP}$ preparation (greater than $98 \%$ ) was verified by thin-layer chromatography. $\left[{ }^{125} \mathrm{I}\right] \mathrm{ICY}$ was added at concentrations ranging from 10 to 100 $\mathrm{pM}$, in the presence or absence of $10 \mu \mathrm{M} l$-alprenolol to distinguish nonspecific from specific binding. The concentration of $l$ alprenolol used was based on preliminary experiments revealing a $50 \%$ inhibiting concentration for radioligand displacement of approximately $0.01 \mu \mathrm{M}$ (34). The incubations were performed over $120 \mathrm{~min}$ at $37^{\circ} \mathrm{C}$ and were terminated by rapid dilution with $4.0 \mathrm{~mL}$ of $20 \mathrm{mM} \mathrm{KH}_{2} \mathrm{PO}_{4}$ buffer, pH 7.4, with $1.0 \mathrm{mM}$ $\mathrm{MgSO}_{4}$ at $37^{\circ} \mathrm{C}$ and separation of bound and free ligand by filtration through Whatman GF/C filters under vacuum, followed by three $4.0-\mathrm{mL}$ rinses of the filters with the same buffer. After drying, the radioactivity collected on each filter was determined by liquid scintillation spectrometry $(68 \%$ counting efficiency). All determinations were performed in duplicate. Binding curves were generated and the $B_{\max }$ and $k_{d}$ for the ligand were determined from the specific binding data by computer analysis using a modification of the program LIGAND by Munson and Rodbard (35) adapted for microcomputers by G. A. McPherson (Elsevier-BIOSOFT, Cambridge, UK) (36). With this protocol $\left[{ }^{125} \mathrm{I}\right] \mathrm{ICY}$ P binding to plasma membranes from fetal lamb VSM reached equilibrium by $90 \mathrm{~min}$, and competitive displacement studies confirmed that radioligand binding was to $\beta$-adrenergic receptors.

Statistical analysis. Analysis of variance with Neuman-Keuls post hoc testing was used to compare the results for cAMP accumulation between the four age groups. $t$ tests were used to compare $\beta$-adrenergic receptor binding characteristics between the two fetal groups. Significance was accepted at the 0.05 level of probability. All results are expressed as mean \pm SEM.

Materials. $l$-Alprenolol and $l$-isoproterenol, as $d$-tartrate and $d$-bitartrate salts, respectively, and forskolin were obtained from Sigma Chemical Co. (St. Louis, MO). All solutions were prepared fresh daily. Forskolin was initially dissolved in $95 \%$ ethanol to yield a stock solution of $10 \mathrm{mM}$. Further dilutions were with Krebs-Henseleit buffer. The amount of ethanol present in the incubations with forskolin (less that $1 \%$ ) had no effect on segment cAMP content when tested alone. ICYP, DL-[ $\left.{ }^{125} \mathrm{I}\right](2200 \mathrm{Ci} /$ $\mathrm{mmol}$ ), and cAMP [ $\left.{ }^{125} \mathrm{I}\right]$ RIA kits were from New England Nuclear/Dupont (Boston, MA).

\section{RESULTS}

CAMP content of untreated segments. The cAMP contents of untreated intrapulmonary arterial segments from the four age groups are shown in Figure 1. cAMP content increased 2.9-fold from early in the 3rd trimester (F1) to later in the 3rd trimester $(\mathrm{F} 2)$, it was similar in the late fetal (F2) and the early postnatal groups (P1), and it increased further (2.2-fold) from the early $(\mathrm{P} 1)$ to the late postnatal group (P2). The net result was an almost

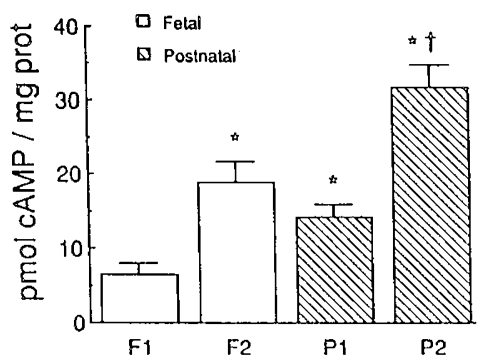

Fig. 1. cAMP content of untreated intrapulmonary arterial segments. cAMP content was determined after equilibration for $20 \mathrm{~min}$. Values are mean \pm SEM for six to 12 segments from three to six sheep. ${ }^{*}, p<0.05$ vs $\mathrm{F} 1 ; \dagger, p<0.05$ vs $\mathrm{P} 1$. 5-fold increase in the cAMP content of the segments over the prenatal and postnatal period examined.

Time courses for $C A M P$ accumulation. The time courses for the increases in segment cAMP content with basal accumulation (nonstimulated, IBMX alone) and accumulation with exogenous stimulation (IBMX plus isoproterenol or IBMX plus forskolin) are depicted in Figure 2. These data are for intrapulmonary arterial segments from $\mathrm{F} 2$ fetal lambs. Basal cAMP accumulation was not significant until $10 \mathrm{~min}$ of incubation, and it was relatively unchanged thereafter. The increase in cAMP content with isoproterenol stimulation was detectable and maximal by 2 min of incubation, and it was stable over the ensuing $18 \mathrm{~min}$. The increase with forskolin stimulation was dramatic initially and reached a maximum at $15 \mathrm{~min}$ of incubation. Similar time courses were obtained in the other three age groups. As such, cAMP accumulation was compared between the four age groups by examining the increase in cAMP content at the shortest durations of incubation at which the maximal effects were obtained, namely at $10 \mathrm{~min}$ for basal accumulation (IBMX alone), at $2 \mathrm{~min}$ for IBMX plus isoproterenol, and at $15 \mathrm{~min}$ for IBMX plus forskolin. These procedures follow those previously used by other investigators $(18,20)$.

Basal CAMP accumulation. The results for basal cAMP accumulation in the four age groups are shown in Figure 3. Basal accumulation was similar in the early (F1) and late fetal groups (F2), it increased 8-fold from late in gestation (F2) to early in the postnatal period (P1), and it did not change over the postnatal period examined ( $\mathrm{P} 1$ versus $\mathrm{P} 2)$.

cAMP accumulation with isoproterenol or forskolin stimulation. cAMP accumulation with isoproterenol stimulation is depicted in Figure 4. Accumulation of the cyclic nucleotide with $\beta$-adrenergic receptor activation increased 5.9-fold from the first half $(\mathrm{F} 1)$ to the second half $(\mathrm{F} 2)$ of the 3rd trimester, and it was similar late in gestation (F2) compared with the postnatal period (P1 and P2). In the postnatal groups, the increase in cAMP content at 2 min of incubation with IBMX plus isoproterenol (Fig. 4) was similar to that obtained at $10 \mathrm{~min}$ with IBMX alone (Fig. 3). This is because in P1 and P2 segments IBMX plus isoproterenol caused an increase in cAMP content at a much

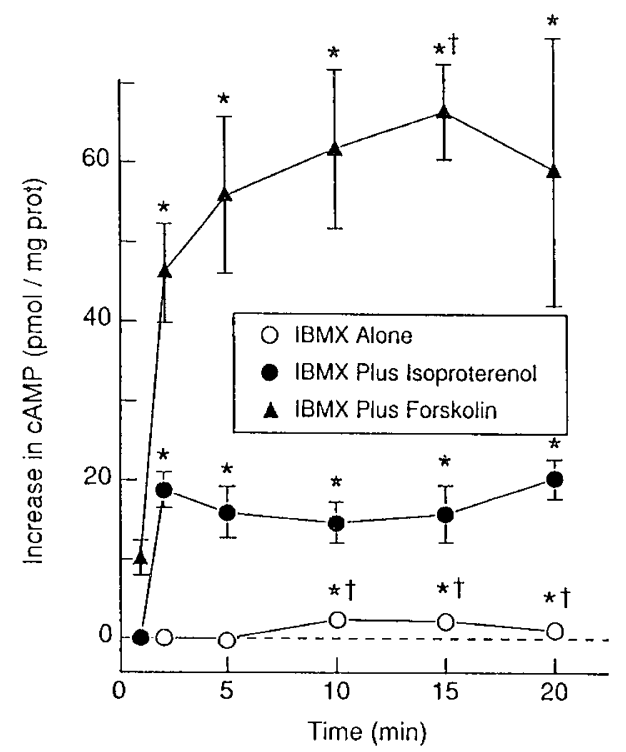

Fig. 2. Time courses for the increases in segment cAMP content with basal accumulation and accumulation with exogenous stimulation. The arterial segments were incubated in the presence of $100 \mu \mathrm{M}$ IBMX alone, with IBMX plus $10 \mu \mathrm{M}$ isoproterenol, or with IBMX plus $100 \mu \mathrm{M}$ forskolin. Values are mean \pm SEM for three experiments performed in duplicate with F2 intrapulmonary arterial segments. For some data points, the error bars are smaller than the symbols depicting the mean values. *, $p<0.05$ vs $1 \mathrm{~min} ; \dagger, p<0.05$ vs $2 \mathrm{~min}$. 


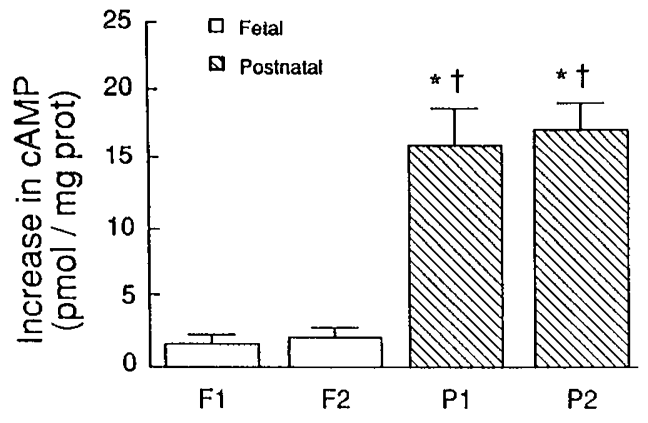

Fig. 3. Basal (nonstimulated) CAMP accumulation. The increase in cAMP content was determined in segments incubated for $10 \mathrm{~min}$ in the presence of $100 \mu \mathrm{M}$ IBMX. Values are mean \pm SEM for six to 12 segments from three to six sheep. ${ }^{*}, p<0.05$ vs $\mathrm{F} 1 ; \dagger, p<0.05$ vs $\mathrm{F} 2$.

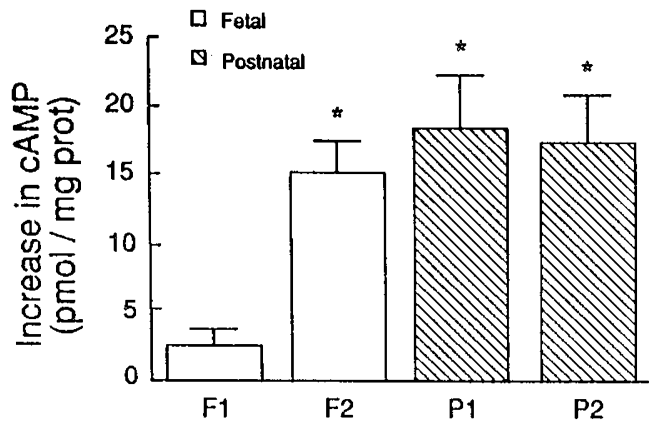

Fig. 4. CAMP accumulation with isoproterenol stimulation. The increase in cAMP content was determined in intrapulmonary arterial segments incubated for $2 \mathrm{~min}$ in the presence of $100 \mu \mathrm{M}$ IBMX and 10 $\mu \mathrm{M}$ isoproterenol. Values are mean $\pm \mathrm{SEM}$ for six to 12 segments from three to six sheep. ${ }^{*}, p<0.05$ vs F1.

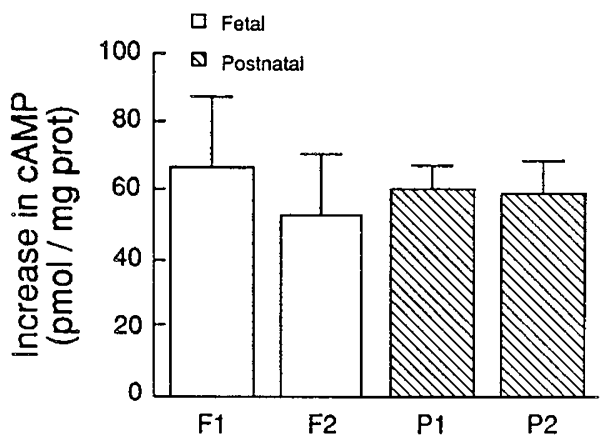

Fig. 5. cAMP accumulation with forskolin stimulation. The increase in cAMP content was determined in intrapulmonary arterial segments incubated for $15 \mathrm{~min}$ in the presence of $100 \mu \mathrm{M}$ IBMX and $100 \mu \mathrm{M}$ forskolin. Values are mean \pm SEM for six to 12 segments from three to six sheep.

greater rate than the increase with IBMX alone, but the maximal increase achieved with continued incubation was similar for the two treatment regimens (data not shown).

The results with forskolin stimulation are given in Figure 5. The increase in cAMP content with postreceptor activation of the adenylate cyclase system was similar in all four study groups, with mean values ranging from 54 to $67 \mathrm{pmol} \mathrm{cAMP} / \mathrm{mg}$ protein.

$\beta$-Adrenergic receptor binding characteristics. The binding characteristics of $\beta$-adrenergic receptors in the intrapulmonary VSM of F1 and F2 fetuses were compared to determine if the differences in isoproterenol-stimulated cAMP accumulation in those two groups are related to changes in receptor density or affinity. Radioligand binding curves depicted that specific binding of [ $\left.{ }^{125} \mathrm{I}\right] \mathrm{ICYP}$ was saturable and LIGAND analysis of the specific binding data confirmed that a single binding site model was most appropriate $(p<0.05)$. Representative binding curves and the Scatchard plot (37) for [ ${ }^{125}$ I]ICYP binding to membranes prepared from intrapulmonary VSM from F1 fetuses are shown in Figure 6 . The percent specific binding at $k_{d}$ was $80-90 \%$. The density of $\beta$-adrenergic receptors $\left(\mathrm{B}_{\max }\right)$ and the $\mathrm{k}_{\mathrm{d}}$ for radioligand binding for the two fetal groups are listed in Table 1 . $\mathrm{B}_{\max }$ was similar in the two groups, as was the $k_{d} . k_{d}$ values in the $p M$ range confirmed that $\left[{ }^{125} \mathrm{I}\right] \mathrm{ICYP}$ binding to the receptors was of high affinity.

\section{DISCUSSION}

In the present investigation we have examined the ontogeny of the function of the adenylate cyclase system in intrapulmonary arteries from 3rd-trimester fetal and newborn lambs. To our knowledge, this is the first study examining the activity of this critical mediator of pulmonary vasodilatation close to the level
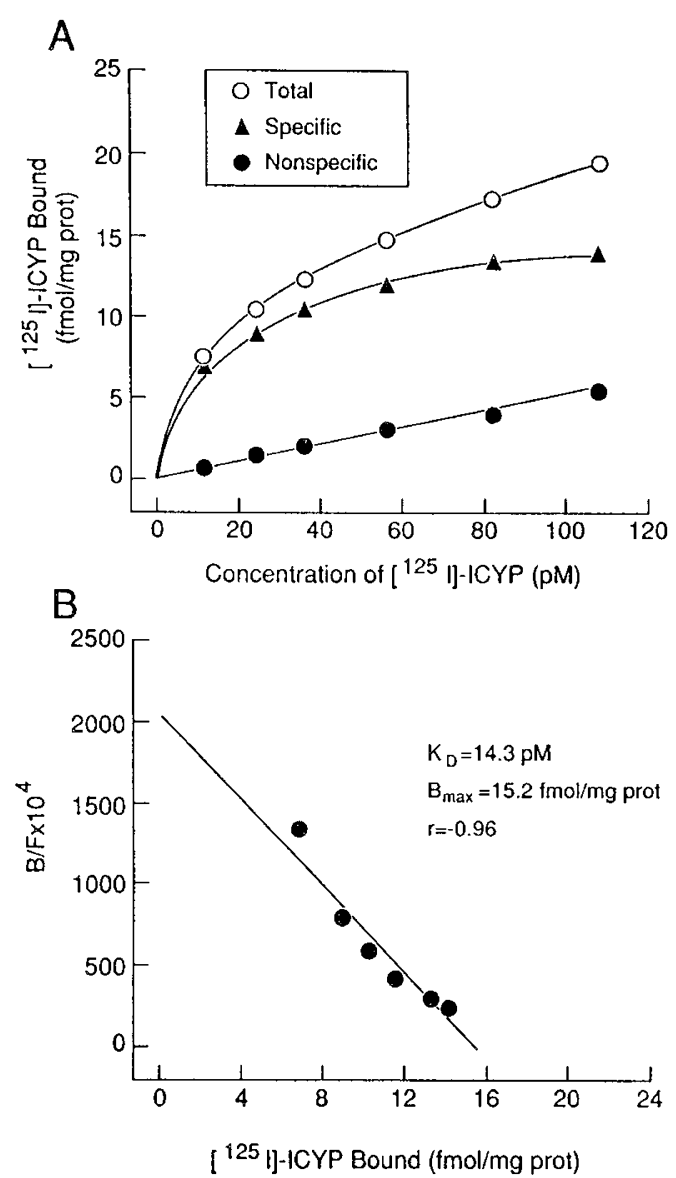

Fig. 6. Panel $A$, representative curves for binding of $\left[{ }^{125} \mathrm{I}\right] \mathrm{ICYP}$ to intrapulmonary VSM plasma membranes from F1 fetal lambs. Membranes were incubated with $10-100 \mathrm{pM}\left[{ }^{125} \mathrm{I}\right] \mathrm{ICYP}$ for $120 \mathrm{~min}$ at $37^{\circ} \mathrm{C}$. Specific binding was defined as [ $\left.{ }^{125} I\right] I C Y P$ binding displacable by $10 \mu \mathrm{M}$ $l$-alprenolol. Total, specific, and nonspecific binding ( $\mathrm{fmol} / \mathrm{mg}$ protein) are plotted as a function of the concentration of $\left[{ }^{125} \mathrm{I}\right] \mathrm{ICYP}(\mathrm{pM})$. Each point was determined in duplicate. Panel $B$, Scatchard plot of specific $\left[{ }^{125} \mathrm{I}\right] \mathrm{ICYP}$ binding to plasma membranes in panel $A$, derived by nonlinear least squares analysis. The ratio $(B / F)$ of bound to free [ $\left.{ }^{125} \mathrm{I}\right] \mathrm{ICYP}$ is plotted as a function of specifically bound $\left[{ }^{125} \mathrm{I}\right] \mathrm{ICYP}$ ( $\mathrm{fmol} / \mathrm{mg}$ protein).

Table 1. $\beta$-Adrenergic receptor binding characteristics in fetal intrapulmonary vascular smooth muscle*

\begin{tabular}{lcc}
\hline & $F 1$ & $F 2$ \\
\hline$B_{\max }($ fmol/mg protein) & $21 \pm 4$ & $21 \pm 6$ \\
Receptor affinity $\left(\mathrm{k}_{\mathrm{d}}\right)(\mathrm{pmol} / \mathrm{L})$ & $29 \pm 5$ & $17 \pm 2$ \\
\hline
\end{tabular}

$* n=3$ experiments. 
of the resistance arteries during late gestation and in the newborn. We have demonstrated that there is an 8-fold increase in nonstimulated cAMP accumulation with phosphodiesterase inhibition from late in gestation (F2) to early in the postnatal period $(\mathrm{P} 1)$, indicating that the basal activity of adenylate cyclase increases dramatically over that phase of development. In addition, increases in the endogenous CAMP content of nontreated segments during the $3 \mathrm{rd}$ trimester (from $\mathrm{F} 1$ to $\mathrm{F} 2$ ) and during the postnatal period (from $\mathrm{P} 1$ to $\mathrm{P} 2$ ) in the absence of apparent alterations in basal adenylate cyclase activity may reflect maturational changes in phosphodiesterase activity. However, conclusions regarding developmental alterations in phosphodiesterase activity should be made with caution because it was not directly measured in this study.

Maturational changes in receptor- and postreceptor-mediated cAMP accumulation were also examined to discern the ontogeny of the function of the components of the adenylate cyclase system. $\beta$-Adrenergic stimulation was studied because the binding characteristics of the VSM receptor can be readily determined to assess whether changes in receptor-mediated cAMP accumulation are related to alterations in $B_{\max }$ or $k_{d}$. We have demonstrated that cAMP accumulation in response to isoproterenol increases almost 6-fold during the 3rd trimester (from F1 to F2) and is then unchanged from late in gestation $(F 2)$ to 1 mo of age (P2). This indicates that the capacity for $\beta$-adrenergic receptormediated regulation of the adenylate cyclase system in ovine intrapulmonary arteries increases during fetal life to reach a postnatal level of maturity by the latter half of the 3 rd trimester. This is not related to an increase in $\beta$-adrenergic receptor number or affinity because the receptor binding characteristics were similar in intrapulmonary VSM from the early (F1) versus the late fetal lambs (F2). Alternatively, these findings are consistent with either changes in the coupling of $\beta$-adrenergic receptors to $\mathrm{G}_{\mathrm{S}}$ or changes in $\mathrm{G}$ protein and/or catalytic subunit function (10). It should be noted that the values presently obtained for $B_{\max }$ and $k_{d}$ in 4 th- to 6 th-generation intrapulmonary VSM from the late fetal lambs (F2) are comparable to those we have previously determined in 3rd- to 6th-generation intrapulmonary VSM from that age group (38).

To assess postreceptor-mediated function of the adenylate cyclase system, cAMP accumulation with forskolin was determined in the four age groups. In studies of the catalytic subunit of adenylate cyclase purified to homogeneity from bovine brain, it has been demonstrated that forskolin stimulates the subunit directly $(39,40)$. However, $G_{s}$ is important for forskolin-elicited stimulation of cAMP synthesis in intact cells because a lack of $\mathrm{G}_{\mathrm{S}}$ or defects in the function of $\mathrm{G}_{\mathrm{S}}$ substantially decrease the response (29). As such, forskolin most likely acts on both $G_{S}$ and the catalytic subunit in the intrapulmonary arterial segments. Our finding that cAMP accumulation with forskolin was similar in the four age groups suggests that postreceptor-mediated mechanisms involving $\mathrm{G}_{\mathrm{S}}$ and the catalytic subunit have already reached a postnatal level of function by the beginning of the 3rd trimester and that there are no changes in the function of these enzyme system components during late gestation. Thus, the results of the present study indicate that there is enhancement in $\beta$-adrenergic receptor-mediated adenylate cyclase activity during the 3rd trimester that may be related to alterations in the coupling of the receptors to $G_{s}$.

It should be emphasized that the cAMP contents determined in the present investigation are the summation of cAMP in both the endothelial and the VSM cells that make up the intrapulmonary arterial segments studied. Adenylate cyclase activity has been demonstrated in endothelial cells, but comparisons of enzyme activity in endothelial and VSM cells cultured from the same artery type suggest that activity is considerably greater in the VSM $(41,42)$. Furthermore, the vast majority of the cells examined in the present study are VSM, and as a result the cAMP measured primarily represents VSM cAMP. However, the role of adenylate cyclase in the endothelial cells should not be ignored, because agonist activation of the enzyme in the endothelial cells may enhance the vasodilatation resulting from the activation of the enzyme in the VSM by the same agonist by mechanisms that may or may not involve the release of endothelium-derived relaxing factor (43).

Developmental changes in $\beta$-adrenergic receptor-mediated mechanisms have been previously reported in studies of main pulmonary arteries from postnatal animals. Park et al. (44) demonstrated that isoproterenol-stimulated relaxation of rabbit main pulmonary artery increases during the 1 st mo of postnatal life (44). In all the age groups examined, the maximal response was found at approximately the same concentration of isoproterenol, and the shifts in the dose-response curves with propranolol were parallel and of the same magnitude (44). This suggests that the age-related differences that they observed in $\beta$-adrenergic responsiveness involved changes beyond the level of receptor activation, conclusions similar to those we have drawn in the present investigation. As for the pulmonary arteries of older rabbits, Fleisch and Hooker (45) demonstrated a decline in relaxation induced by isoproterenol from 2 to 25 mo of age. Similarly, O'Donnell and Wanstall (46) reported progressively decreasing isoproterenol-stimulated relaxation of main pulmonary artery rings from rats $1-2$ mo to 18 mo of age. Taking into consideration that different species and stages of development have been examined, the results of these and the present studies suggest that maturational changes may occur in the adenylate cyclase system of the pulmonary artery to optimize the function of this mediator of vasodilatation in the late fetus and newborn. It is postulated that alterations in these maturational processes during fetal life would contribute to the development of pulmonary hypertension in the neonate.

Acknowledgments. The authors thank Ronald R. Magness, Ph.D., for his support and his assistance in obtaining the arterial segments and Marilyn Dixon for preparing the manuscript.

\section{REFERENCES}

1. Leffler CW, Hessler JR 1979 Pulmonary and systemic vascular effects of exogenous prostaglandin $I_{2}$ in fetal lambs. Eur $J$ Pharmacol 54:37-42

2. Green R, Rojas J, Sundell H 1979.Pulmonary vascular response to prostacyclin in fetal lambs. Prostaglandins 18:927-934

3. Lock JE, Olley PM, Coceani F 1980 Direct pulmonary vascular responses to prostaglandins in the conscious newborn lamb. Am J Physiol 238:H631H638

4. Lock JE, Olley PM, Coceani F 1981 Enhanced beta-adrenergic receptor responsiveness in hypoxic neonatal pulmonary circulation. Am J Physiol 240:H697-H703

5. Lock JE, Olley PM, Soldin S, Coceani F 1980 Indomethacin-induced pulmonary vasoconstriction in the conscious newborn lamb. Am J Physiol 238:H639-H651

6. Green RS, Leffler CW 1984 Hypoxia stimulates prostacyclin synthesis by neonatal lungs. Pediatr Res 18:832-835

7. Tyler T, Wallis R, Leffler C, Cassin S 1975 The effects of indomethacin on the pulmonary vascular response to hypoxia in the premature and mature newborn goat. Proc Soc Exp Biol Med 150:695-698

8. Leffler CW, Tyler TL, Cassin S 1978 Effect of indomethacin on pulmonary vascular response to ventilation of fetal goats. Am J Physiol 235:H346-H351

9. Davidson D 1988 Pulmonary hemodynamics at birth: effects of acute cyclooxygenase inhibition in lambs. J Appl Physiol 64:1676-1682

10. Gilman AG $1987 \mathrm{G}$ proteins: transducers of receptor-generated signals. Annu Rev Biochem 56:615-649

11. Kukovetz WR, Holzmann S, Wurm A, Poch G 1979 Prostacyclin increases cAMP in coronary arteries. J Cyclic Nucleotide Res 5:469-476

12. Oliva D, Noe A, Nicosia S, Bernini F, Fumagalli R, Whittle BJR, Moncada S, Vane JR 1984 Prostacyclin-sensitive adenylate cyclase in cultured myocytes: differences between rabbit aorta and mesenteric artery. Eur J Pharmacol 105:207-213

13. Lewis AB, Heymann MA, Rudolph AM 1976 Gestational changes in pulmonary vascular responses in fetal lambs in utero. Circ Res 39:536-541

14. Morin FC, Egan EA, Ferguson W, Lundgren CEG 1988 Development of pulmonary vascular response to oxygen. Am J Physiol 254:H542-H546

15. Katsuki S, Murad F 1977 Regulation of adenosine cyclic $3^{\prime}, 5^{\prime}$-monophosphate and guanosine cyclic $3^{\prime}, 5^{\prime}$-monophosphate levels and contractility in bovine tracheal smooth muscle. Mol Pharmacol 13:330-341

16. Dembinska-Kiec A, Rucker A, Schonhofer PS $1979 \mathrm{PGI}_{2}$ enhances cAMP content in bovine coronary arteries in the presence of isobutylmethylxanthine. Naunyn Schmiedebergs Arch Pharmacol 308:107-110 
17. Holzmann S, Kukovetz WR, Schmidt K 1980 Mode of action of coronary arterial relaxation by prostacyclin. J Cyclic Nucleotide Res 6:451-460

18. Schoeffter P, Stoclet J 1982 Age-related decrease of in vitro isoproterenolinduced cyclic AMP accumulation in rat aorta. Eur J Pharmacol 77:183186

19. Kramer GL, Wells JN 1979 Effects of phosphodiesterase inhibitors on cyclic nucleotide levels and relaxation of pig coronary arteries. Mol Pharmacol $16: 813-822$

20. Nakagawa H, Oka M, Kimura A, Ohuchi T 1986 Effects of age on the formation of cyclic nucleotides in guinea-pig tracheal smooth muscle in response to pharmacological agents. Eur J Pharmacol 125:211-216

21. Wendelberger KJ 1987 Prostaglandin and leukotriene receptors in pulmonary, vascular, and uterine smooth muscle. Semin Perinatol 11:1-11

22. Nuwayhid B, Brinkman CR, Su C, Bevan JA, Assali NS 1975 Systemic and pulmonary hemodynamic responses to adrenergic and cholinergic agonists during fetal development. Biol Neonate 26:301-317

23. Levin DL, Rudolph AM, Heymann MA, Phipps RH 1976 Morphological development of the pulmonary vascular bed in fetal lambs. Circulation 53:144-151

24. Popovich KJ, Hiller C, Hough A, Norris JS, Cornett LE 1984 Characterization of a beta-adrenergic receptor in porcine trachealis muscle. Am J Physiol 247:C342-C349

25. Furchgott RF, Zawadzki JV 1980 The obligatory role of endothelial cells in the relaxation of arterial smooth muscle by acetylcholine. Nature 288:373376

26. Murad F 1986 Cyclic guanosine monophosphate as a mediator of vasodilatation. J Clin Invest 78:1-5

27. Seamon KB, Padgett W, Daly JW 1981 Forskolin-unique diterpene activator of adenylate cyclase in membranes and in intact cells. Proc Natl Acad Sci USA 78:3363-3367

28. Laurenza A, Sutkowski EM, Seamon KB 1989 Forskolin: a specific stimulator of adenylyl cyclase or a diterpene with multiple sites of action? Trends Pharmacol Sci 10:442-447

29. Seamon KB, Daly JW 1986 Forskolin: its biological and chemical properties. Adv Cyclic Nucleotide Protein Phosphorylation Res 20:1-150

30. Lowry OH, Rosebrough NJ, Farr AL, Randall RJ 1951 Protein measurement with the folin phenol reagent. J Biol Chem 193:265-275

31. Harper JF, Brooker GJ 1975 Femtomolar sensitive radioimmunoassay for cAMP and cGMP after $2^{\prime} 0$ acetylation by acetic anhydride in aqueou solution. J Cyclic Nucleotide Res 1:207-218
32. Shaul PW, Muntz KH, Buja LM 1990 Comparison of beta-adrenergic receptor binding characteristics and coupling to adenylate cyclase in rat pulmonary artery versus aorta. J Pharmacol Exp Ther 252:86-92

33. Wei J, Janis RA, Daniel EE 1976 Isolation and characterization of plasma membrane from rat mesenteric arteries. Blood Vessels 13:279-292

34. Bylund DB, Yamamura HI 1990 Methods for receptor binding. In: Yamamura HI, Enna SJ, Kuhar MJ (eds) Methods in Neurotransmitter Receptor Analysis. Raven Press, New York, pp 1-35

35. Munson PJ, Rodbard D 1980 LIGAND: a versatile computerized approach for the characterization of ligand binding systems. Anal Biochem 107:220239

36. McPherson GA 1985 Analysis of radioligand binding experiments: a collection of computer programs for the IBM PC. J Pharmacol Methods 14:213-228

37. Scatchard S 1949 The attraction of proteins for small molecules and ions. Ann NY Acad Sci 51:660-672

38. Shaul PW, Magness RR, Muntz KH, DeBeltz D, Buja LM 1990 Alpha-1adrenergic receptors in pulmonary and systemic vascular smooth muscle: alterations with development and pregnancy. Circ Res 67:1193-1200

39. Pfeuffer E, Mollner S, Pfeuffer T 1986 Adenylate cyclase from bovine brain cortex: purification and characterization of the catalytic unit. EMBO J 4:3675-3679

40. Smigel MD 1986 Purification of the catalyst of adenylate cyclase. J Biol Chem 261:1976-1982

41. Schafer Al, Gimbrone MA, Handin RI 1980 Endothelial cell adenylate cyclase: activation by catecholamines and prostaglandin $\mathrm{I}_{2}$. Biochem Biophys Res Commun 96:1640-1647

42. Dembinska-Kiec A, Rucker A, Schonhofer PS 1980 Effects of $\mathrm{PGI}_{2}$ and PG analogs on cAMP levels in cultured endothelial and smooth muscle cells derived from bovine arteries. Naunyn Schmiedebergs Arch Pharmacol 311:67-70

43. Rubanyi G, Vanhoutte PM 1985 Endothelium-removal decreases relaxations of canine coronary arteries caused by beta-adrenergic agonists and adenosine. J Cardiovasc Pharmacol 7:139-144

44. Park MK, Diehl AM, Sunderson JM 1976 Maturation of beta-adrenergic receptor activity of rabbit aorta and pulmonary artery. Life Sci 19:321-328

45. Fleisch JH, Hooker CS 1976 The relationship between age and relaxation of vascular smooth muscle in the rabbit and rat. Circ Res 38:243-249

46. O'Donnell SR, Wanstall JC 1984 Beta-1 and beta-2 adrenoceptor-mediated responses in preparations of pulmonary artery and aorta from young and aged rats. J Pharmacol Exp Ther 228:733-738 